\title{
Genome-wide association study of concentrations of iron and other minerals in longissimus muscle of Angus cattle ${ }^{1}$
}

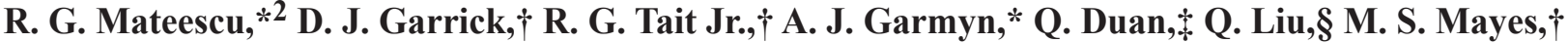 \\ A. L. Van Eenennaam,\# D. L. VanOverbeke,* G. G. Hilton, ${ }^{*}$ D. C. Beitz, $\uparrow \S$ and J. M. Reecy $\dagger$ \\ *Department of Animal Science, Oklahoma State University, Stillwater 74078; $†$ Department \\ of Animal Science, Iowa State University, Ames 50011; \$Department of Genetics, University of \\ North Carolina, Chapel Hill 27599; §Department of Biochemistry, Biophysics and Molecular Biology, \\ Iowa State University, Ames 50011; and \#Department of Animal Science, University of California, Davis 95616
}

\begin{abstract}
The objective of this study was to characterize variation and identify SNP and chromosomal regions associated with mineral concentrations in LM of Angus beef cattle. Samples of LM from 2,285 Angus cattle were obtained, and concentrations of 7 minerals, including iron, magnesium, manganese, phosphorus, potassium, sodium, and zinc, were quantified. Genomic DNA extracted from the ground beef sample used for mineral composition was genotyped with the Bovine SNP50 Infinium II BeadChip, and effects of SNP on each trait were estimated using the Bayes-C $\pi$ module of GenSel software. Pedigree-based estimates of heritabilities and corresponding genetic variances indicate iron was the only mineral concentration that could be considered a good candidate for manipulation by genomic selection. The amount of variation that could be accounted for by SNP genotypes was concordant with pedigree-based heritabilities and varied from very low for potassium and sodium $(<0.09)$ to medium high (0.37) for iron. Although significant chromosomal regions were identified for all minerals analyzed in this study, further study focused on iron. Seven regions on
\end{abstract}

6 chromosomes $(1,2,7,10,15$, and 28$)$ were identified to have a major effect on the iron content of LM in Angus cattle. The accuracy of direct genomic values (DGV) for iron concentration was estimated using a 5 -fold cross-validation strategy. The accuracy of DGV estimated as the genetic correlation between DGV and the phenotype (iron concentration) adjusted for contemporary groups was 0.59 . A bivariate animal model was used to estimate genetic correlations between iron concentrations and a reduced set of economically important carcass traits: HCW, rib eye area, calculated USDA yield grade, percent KPH, and marbling score. The genetic correlations between iron concentration and $\mathrm{HCW}$, percentage $\mathrm{KPH}$, marbling score, and rib eye area were small (-0.19 to 0.15$)$ and nonsignificant. Although still weak (0.22), a positive significant genetic correlation was identified between iron content and USDA calculated yield grade. Beef is a major contributor of iron and zinc in the human diet, and this study found that iron content might be effectively manipulated through marker-assisted selection programs, without compromising other carcass and palatability traits.

Key words: beef, genome-wide association, genomic breeding values, mineral concentration

(C) 2013 American Society of Animal Science. All rights reserved.

\section{INTRODUCTION}

Genomic selection provides new opportunities in animal breeding. It is now possible to genotype cattle for at least 50,000 SNP, to estimate the marker effects from

\footnotetext{
${ }^{1}$ This research was supported by Pfizer Animal Genetics.

${ }^{2}$ Corresponding author: raluca@okstate.edu

Received November 7, 2012.

Accepted May 22, 2013.
}

J. Anim. Sci. 2013.91:3593-3600 doi:10.2527/jas2012-6079

an analysis of a population with SNP genotypes and trait phenotypes, and to use them to generate direct genomic values (DGV), as proposed by Meuwissen et al. (2001). With this technology, we now have the ability to select for difficult-to-improve traits (i.e., traits expressed in only 1 sex or late in life, traits that require individuals to be sacrificed, or traits expensive to measure).

Consumers today are increasingly interested in a healthful diet. Meat is recognized as an important source of protein, vitamin $B_{12}$, Vitamin $D$, and essential omega 
3 fatty acids, as well as bioavailable minerals such as iron and zinc. The challenge for industry is to use the opportunities provided by genomics and respond to concerns of consumers with respect to healthfulness of beef. If improving healthfulness of beef is deemed important for the industry, increasing iron and zinc concentration should receive priority as they are important minerals for human health and beef is one of the best dietary source of these minerals (Zanovec et al., 2010), which are well absorbed by the body. These traits are impractical to improve through traditional selection but are ideal candidates for genomic selection if genetic markers that account for a worthwhile proportion of the variation could be identified.

The objectives of this study were to estimate additive genetic variability and heritability of concentrations of minerals in LM of Angus beef cattle, to carry out a genomewide association study to identify chromosomal regions associated with these traits, and to explore the feasibility of using genomic selection to increase iron concentration.

\section{MATERIALS AND METHODS}

The Iowa State University and Oklahoma State University Institutional Review Boards approved the experimental protocol used in this study.

\section{Animals and Sample Collection}

A total of 2,285 Angus-sired bulls $(n=540)$, steers $(n=1,311)$, and heifers $(n=434)$ sired by 155 sires were used in this study. All cattle were finished on concentrate diets in Iowa $(n=1,085)$, California $(n=360)$, Colorado $(n=388)$, or Texas $(n=452)$. Animals were harvested at commercial facilities when they reached typical U.S. market end points, with an average age of $457 \pm 46 \mathrm{~d}$. Production characteristics and additional details of the sample collection and preparation of these cattle were reported previously (Garmyn et al., 2011). After external fat and connective tissue were removed, the $1.27-\mathrm{cm}$ steaks were freeze-ground in liquid nitrogen to produce a powder that was analyzed for nutrient composition. Nutrient composition analysis was conducted at Iowa State University (Ames, IA).

\section{Minerals Concentration}

Mineral content of LM samples was determined by inductively coupled plasma-optical emission spectroscopy (ICP-OES; SPECTRO Analytical Instruments, Mahwah, NJ). The samples were dried at $105^{\circ} \mathrm{C}$ for 18 to $20 \mathrm{~h}$ according to AOAC official method 934.01 (AOAC, 2005), and moisture content was calculated. Dried samples were subjected to a closed-vessel microwave digestion process (CEM, MDS-2000, Matthews,
$\mathrm{NC)}$ with $5 \mathrm{~mL}$ concentrated nitric acid and $2 \mathrm{~mL} \mathrm{30 \%}$ hydrogen peroxide according to AOAC official methods 999.10 (Jorhem and Engman, 2000). The microwave was programmed as follows: $250 \mathrm{~W}$ for $5 \mathrm{~min}, 630 \mathrm{~W}$ for $5 \mathrm{~min}, 500 \mathrm{~W}$ for $20 \mathrm{~min}$, and $0 \mathrm{~W}$ for $15 \mathrm{~min}$. Digested samples were transferred to $25-\mathrm{mL}$ volumetric flasks and diluted with deionized water. The concentrations of iron, magnesium, manganese, phosphorus, potassium, sodium, and zinc were then measured by ICP-OES as previously described (Garmyn et al., 2011).

\section{Heritability of Mineral Concentration}

The phenotypes were used to estimate heritability from pedigree information for each mineral based on a single-trait animal model fitted using a REML procedure implemented in WOMBAT (Meyer, 2007; http:// didgeridoo.une.edu.au/km/wombat.php).

In matrix notation, the basic model equation was

$$
\mathbf{Y}=\mathbf{X} \beta+\mathbf{Z} u+e,
$$

where the design matrices $\mathbf{X}$ and $\mathbf{Z}$ relate phenotypic observations in the vector $\mathbf{Y}$ to fixed $(\beta)$ and random $(u)$ effects, respectively. The vector $e$ contains random residual effects specific to animals. The vectors of $u$ and $e$ effects were assumed to be normally distributed with means of $\mathbf{0}$ and variances $\mathbf{A} \sigma^{2}{ }_{a}$ and $\mathbf{I} \sigma^{2}{ }_{e}$, respectively. The matrix $\mathbf{I}$ is an identity matrix of order equal to the number of animals with mineral observations, $\mathbf{A}$ is the additive relationship matrix, $\sigma^{2}$ is the additive genetic variance, and $\sigma_{\mathrm{e}}^{2}$ is the residual variance.

Contemporary groups were defined on the basis of cross classifications of gender at harvest (bull, heifer, or steer), finishing location (CA, CO, IA, TX), and harvest date, for a total of 33 groups. The 33 contemporary groups were fit as fixed effects.

A 5-generation pedigree file with 5,907 individuals containing the identification of the animal, sire, and dam was used to define relationships among animals in the data set.

\section{Genome-Wide Association Study}

Genomic DNA was extracted from the ground beef sample used for mineral composition and was genotyped with the Bovine SNP50 Infinium II BeadChip (Illumina, San Diego, CA) for collection of high-density SNP genotypes. Contemporary groups were fit as fixed effects in genomic analyses. Effects of SNP on each trait were estimated using the Bayes- $\mathrm{C}$ module of the GenSel 4.0.1 program (Habier et al., 2011 ; http://bigs.ansci.iastate.edu/). The values for $\pi$ were $0.996,0.96,0.999,0.96,0.988$, 0.96 , and 0.995 for iron, magnesium, manganese, phosphorus, potassium, sodium, and zinc, respectively. When 
Bayes-C $\pi$ estimated $\pi$ to be less than $0.96, \pi$ was raised to 0.96 so that the number of SNP markers did not exceed the number of animals in the analyses. The Markov chain Monte Carlo approach used to estimate the effect of each SNP involved a 1,000-iteration burn-in period followed by 40,000 iterations used to obtain the posterior mean effect of each SNP (Kizilkaya et al., 2010).

The posterior means of the SNP effects were collectively used to predict the genomic merit of sliding chromosomal regions, and the variance of the DGV of these windows across individuals was expressed as a proportion of the total variance (Fernando and Garrick, 2010). The estimate of the proportion of genetic variation explained by each window obtained from the genome-wide association study was plotted against genome region using SNPLOTz v.1.52 (Hu et al., 2010 ; www.animalgenome.org/bioinfo/tools/snplotz/). Individual SNP in windows that explained the largest proportion of genetic variation were then visualized in GBrowse (Stein et al., 2002; /www.animalgenome.org/cgi-bin/gbrowse/bovine/) to allow for a detailed inspection of the chromosomal region containing the specific SNP. Gene searches were performed for these genomic regions containing SNP with the greatest genetic variances.

\section{Direct Genomic Value and Accuracy of Direct Genomic Value for Iron Concentration}

The DGV for individual i was derived by multiplying the number of copies of $\mathrm{B}$ alleles by their corresponding posterior mean SNP effect and summing these values over all $\mathrm{k}$ marker loci:

$$
\operatorname{DGV}_{\mathrm{i}}=\sum_{(\mathrm{j}=1)}^{\mathrm{k}} \mathrm{z}_{\mathrm{ij}} \hat{\mathrm{u}}_{\mathrm{j}}
$$

where $\mathrm{DGV}_{\mathrm{i}}$ is the $\mathrm{DGV}$ for individual $\mathrm{i}, \mathrm{z}_{\mathrm{ij}}$ is the marker genotype of individual i for marker $j$, and is the posterior mean effect of marker $\mathrm{j}$ obtained from the 40,000 postburn-in samples. The accuracy of DGV is critical in determining if genomic selection can be successful. To assess the accuracy of DGV a 5-fold cross-validation strategy was used. The K-means clustering method was used to partition the resource population into 5 mutually exclusive groups based on additive relationships determined from a 5-generation pedigree, such that the relatedness among individuals was maximized within group and minimized between groups (Saatchi et al., 2011). For each analysis, the training population consisted of 4 groups to estimate marker effects, which were then used to predict DGV of the animals in the fifth group (validation group). At the end of the 5-fold analyses, every animal in the resource population had a DGV obtained when the individual was a member of the validation group and its molecular breeding value had
Table 1. Genetic variance, residual variance, and heritability and its sampling error for mineral concentrations $(\mu \mathrm{g} / \mathrm{g}$ of meat) in LM of Angus cattle estimated with a restricted maximum likelihood procedure based on a single-trait animal model fitted to the data using WOMBAT software (Meyer, 2007; http://didgeridoo. une.edu.au/km/wombat.php)

\begin{tabular}{lcccc}
\hline \hline Mineral & $\begin{array}{c}\text { No. of } \\
\text { observations }\end{array}$ & $\begin{array}{c}\text { Genetic } \\
\text { variance }\end{array}$ & $\begin{array}{c}\text { Residual } \\
\text { variance }\end{array}$ & $\begin{array}{c}\text { Heritability } \\
\pm \text { SE }\end{array}$ \\
\hline Iron & 2,228 & 3.14 & 3.42 & $0.48 \pm 0.08$ \\
Magnesium & 2,241 & 0.003 & 554.63 & $0.000 \pm 0.02$ \\
Manganese & 1,978 & 0.000002 & 0.0014 & $0.000 \pm 0.02$ \\
Phosphorus & 2,239 & 0.02 & 30790 & $0.000 \pm 0.02$ \\
Potassium & 2,192 & 2.08 & 107347 & $0.000 \pm 0.02$ \\
Sodium & 2,240 & 460.10 & 2627.20 & $0.15 \pm 0.05$ \\
Zinc & 2,228 & 3.09 & 47.12 & $0.06 \pm 0.04$ \\
\hline
\end{tabular}

been obtained without using its own phenotype.

The accuracy of DGV can be defined by their correlation with true breeding values. The true breeding values are unknown, and the only available information to measure the accuracy is the phenotypes. The accuracy of DGV was assessed from the genetic correlation between DGV and the phenotype. A bivariate animal model was used by extending the model in Eq. [1] to include a second trait. The 2 traits were DGV and phenotype, with an effect for each fold fitted as fixed effects for genomic merit and contemporary groups fitted as fixed effects for the phenotype.

The extent of prediction bias when using DGV was assessed by regression of the phenotypes (adjusted for the contemporary groups) on DGV, pooled across each fold.

To assess the potential consequences if iron concentration is included in the breeding goal, bivariate animal models were used to estimate genetic correlations between iron concentrations and $\mathrm{HCW}$, rib eye area, calculated USDA yield grade, percent $\mathrm{KPH}$, and marbling score.

\section{RESULTS AND DISCUSSION}

\section{Heritability of Mineral Concentration}

The genetic and residual variances as well as heritabilities were estimated for each mineral using a classic animal model that partitions phenotypic variation into its 2 components (genetic and residual) on the basis of the pedigree relationships among animals (Table 1). Iron had the largest heritability (0.48), followed by sodium $(0.15)$ and zinc $(0.06)$, whereas heritability for magnesium, manganese, phosphorus, and potassium were 0 .

The discovery process generates an estimate, similar to heritability, of the proportion of phenotypic variation that can be accounted for using SNP markers (Table 2). The proportion of phenotypic variance explained by SNP genotypes varied from very low for potassium and so- 
dium $(<0.09)$, indicating that the marker predictions will be poor, to relatively medium high for iron (0.37), indicating that markers may have adequate predictive power.

The estimated phenotypic variance (the sum of the 2 components) is very similar for the 2 models, but its partition is different. On the basis of the present data set, comparing the proportion of phenotypic variance explained by SNP genotypes in Table 2 with heritability estimates in Table 1 shows that for iron and sodium, which have medium and low heritability ( 0.48 and 0.15 , respectively), the additive genetic variance explained by the markers is smaller ( 0.37 and 0.09 as proportion of total variance, respectively), and this might be related to a phenomenon known as missing heritability (Visscher et al., 2008). For all other minerals with very low or 0 heritability, the variance explained by the markers is greater, relative to the size of the estimated additive genetic variance explained by familial relationships. This likely reflects the fact that some of the 54,000 SNP can spuriously fit data with no real genetic basis. Additional studies, ideally on larger data sets, will be necessary in the future to provide a clearer picture of the genetic architecture underlying these traits and to help improve our knowledge of the real genetic associations.

\section{Genome-Wide Association Study}

Results of the genome-wide association study for mineral content including chromosomal location, number of SNP, and the percentage of genetic variation explained by these chromosomal regions are presented in Table 3. Although significant regions were identified for all minerals analyzed in this study, considering the heritability estimates and the proportion of total variance explained by the markers, the best candidate mineral for genomic selection was iron concentration in muscle; therefore, only results for that trait are discussed below.

Iron is a key element in human metabolism and an essential component of hundreds of proteins and enzymes (Beard and Dawson, 1997; Wood and Ronnenber, 2006). Although iron deficiency is a major public health problem worldwide (Andrews, 2008), beef contains the greatest amount of iron compared with other meat sources (Carpenter and Clark, 1995). In this study, 7 regions on 6 chromosomes $(1,2,7,10,15$, and 28) were identified to have a major effect on iron content of LM in Angus cattle. Many of these chromosomal regions contain, or are in close proximity to, genes associated with iron homeostasis or iron metabolism, providing strong candidate genes for further investigation as well as confirming the validity of the genome-wide association results. A number of the most important candidate genes are discussed below.

One strongly associated region on BTA1 harbors a critical iron-related gene, transferrin receptor protein 1
Table 2. Posterior means of variance components explained by genome-wide SNP markers for minerals content $(\mu \mathrm{g} / \mathrm{g}$ of meat) in Angus cattle estimated using the Bayes-C module of GenSel software (Habier et al., 2011 ; http://bigs.ansci.iastate.edu/)

\begin{tabular}{lccccc}
\hline \hline & No. of & Genetic & Residual & Proportion of \\
Trait & animals & variance & variance & $\begin{array}{c}\text { explained by markers } \\
\text { explc variance }\end{array}$ \\
\hline Iron & 2,228 & 2.42 & 4.13 & 0.37 & 0.996 \\
Magnesium & 2,241 & 100.93 & 466.64 & 0.18 & 0.960 \\
Manganese & 1,978 & 0.0003 & 0.001 & 0.20 & 0.999 \\
Phosphorus & 2,239 & 3695.88 & 27376.70 & 0.12 & 0.960 \\
Potassium & 2,240 & 3391.91 & $105,406.00$ & 0.03 & 0.988 \\
Sodium & 2,228 & 269.24 & 2831.57 & 0.09 & 0.960 \\
Zinc & 2,228 & 8.49 & 42.58 & 0.17 & 0.995 \\
\hline
\end{tabular}

(TfR1), a membrane protein required for iron delivery from transferrin to cells via receptor-mediated endocytosis (Graham et al., 2007), and has been shown to be inversely regulated by cellular iron status via the posttranscriptional iron responsive element-iron regulatory protein (IRE-IRP) mechanism (Eisenstein, 2000). The uptake of iron from transferrin is controlled by TfR 1 expression, which is modulated by intracellular iron concentrations via iron-regulatory proteins (Hentze and Kuhn, 1996). To add further complexity, the interaction of transferrin with the TfR 1 is also regulated by the competitive binding of the hemochromatosis protein (HFE) that is mutated in the iron-loading disease hemochromatosis (Chen et al., 2007). This molecule assembles with $\beta 2$-microglobulin ( $\beta 2-\mathrm{m})$ to form a complex that binds to the TfR 1 at a site involved in transferrin binding (Lebron et al., 1999). The bovine TfRl gene is located on chromosome 1 , about $9 \mathrm{Mb}$ from the most significant region on BTA1 associated with iron content in the present study. The other transferrin receptor (TfR2), more recently identified, is unresponsive to intracellular iron levels (Kawabata et al., 2001), but its expression is also regulated by HFE. The bovine gene encoding TfR2 is located on BTA 25, and after a candidate gene study, our group has recently reported an association between genetic polymorphisms in TfR2 and beef iron content (Duan et al., 2012). This region of the genome does not appear to be one of the larger regions associated with iron content, reinforcing the importance of genomewide scans in identifying a larger array of genes underlying the genetic variation of complex traits than can be found by candidate gene studies alone. These 2 different approaches are complementary.

Two possible candidate genes near the greatest significant chromosomal region on BTA 2 are solute carrier family 11 (proton-coupled divalent metal ion transporters) member 1 (SLC11A1) and aldehyde oxidase 1 (AOX1). The SLC11A1 (formerly known as NRAMP1) 
Table 3. Chromosome (BTA), location, number of SNP, and percent genetic variation explained by chromosomal regions associated with mineral content in LM of Angus cattle

\begin{tabular}{|c|c|c|c|c|}
\hline Trait & $\mathrm{BTA}^{1}$ & $\begin{array}{c}\text { Location } \\
\text { (start to end, } \mathrm{Mb} \text { ) }\end{array}$ & $\begin{array}{l}\text { No. of } \\
\text { SNP }\end{array}$ & $\begin{array}{l}\text { Percent Variation } \\
\text { explained by SNP }\end{array}$ \\
\hline Iron & 15 & 56.00 to 56.99 & 22 & 4.76 \\
\hline Iron & 7 & 93.01 to 93.88 & 11 & 2.82 \\
\hline Iron & 1 & 62.05 to 62.99 & 22 & 1.52 \\
\hline Iron & 7 & 73.01 to 73.94 & 29 & 1.35 \\
\hline Iron & 2 & 103.01 to 103.99 & 16 & 1.33 \\
\hline Iron & 28 & 24.01 to 24.97 & 22 & 1.25 \\
\hline Iron & 10 & 81.02 to 81.98 & 25 & 1.08 \\
\hline Iron & 10 & 32.01 to 32.99 & 24 & 1.07 \\
\hline Iron & 15 & 11.009 to 11.78 & 14 & 1.00 \\
\hline Magnesium & 17 & 7.04 to 7.99 & 26 & 0.16 \\
\hline Magnesium & 1 & 81.02 to 81.89 & 28 & 0.14 \\
\hline Magnesium & 19 & 42.09 to 42.98 & 23 & 0.11 \\
\hline Magnesium & 22 & 5.02 to 5.99 & 28 & 0.11 \\
\hline Magnesium & $\mathrm{X}$ & 108.14 to 108.97 & 15 & 0.10 \\
\hline Zinc & 18 & 46.03 to 46.99 & 26 & 1.28 \\
\hline Zinc & 11 & 42.07 to 42.97 & 18 & 1.19 \\
\hline Zinc & 6 & 103.03 to 103.97 & 27 & 0.81 \\
\hline Zinc & 7 & 94.11 to 94.97 & 15 & 0.79 \\
\hline Zinc & 8 & 53.01 to 53.98 & 21 & 0.61 \\
\hline Zinc & $\mathrm{X}$ & 5.28 to 5.92 & 12 & 0.59 \\
\hline Zinc & 2 & 123.15 to 123.99 & 24 & 0.55 \\
\hline Zinc & 10 & 88.04 to 88.96 & 27 & 0.51 \\
\hline Phosphorus & 5 & 114.01 to 114.86 & 5 & 0.13 \\
\hline Phosphorus & 17 & 7.04 to 7.99 & 17 & 0.12 \\
\hline Phosphorus & 9 & 23.00 to 23.94 & 9 & 0.11 \\
\hline Potassium & 22 & 5.02 to 5.99 & 28 & 0.17 \\
\hline Sodium & 1 & 52.03 to 52.98 & 25 & 0.09 \\
\hline Sodium & 5 & 40.06 to 40.96 & 29 & 0.09 \\
\hline
\end{tabular}

has been shown to play a general role in macrophage function within the endocytic pathway. There is a link between SLC11A1 function and iron metabolism, as SLC11A1 acts as an iron pump that depletes the phagosomal compartments of this nutrient, therefore influencing pathogen growth within the macrophage through starvation of the pathogen of iron (Brown et al., 1997; Gomes and Appelberg, 1998). Other genes related to iron transport and in near proximity to significant chromosomal regions in this study include erythrocyte membrane protein band 4.2 (EPB 42) on BTA 10, prolyl 4-hydroxylase, $\alpha$ polypeptide III $(\boldsymbol{P} 4 \boldsymbol{H A 3})$ and butyrobetaine $(\gamma), 2$-oxoglutarate dioxygenase ( $\gamma$-butyrobetaine hydroxylase) 1 (BBOX1) on BTA 15, and prolyl 4-hydroxylase, $\alpha$ polypeptide I (P4HA1) on BTA 28.

Zinc is an essential mineral with several positive roles, including growth and development, boosting immunity, improving the ability of the body to heal wounds, and maintaining normal blood glucose concentrations. Although several animal and plant foods supply zinc in the human diet, similar to iron, zinc is better absorbed from beef (Nicklas et al., 2012). Zinc content has a low heritability (0.06), but it has a substantial genetic correlation (0.49) with iron content in LM of Angus cattle (Mateescu et al., 2013). It is therefore of interest to see if this genetic correlation can be explained at the genomic level by finding pleiotropic genes.

Several genomic regions on BTA 2, 7, and 10 were identified in this study to be associated with both iron and zinc content, which indicates that some common gene networks may control both the iron and zinc content in LM. These regions contain several genes likely to be associated with both iron and zinc transport, metabolism, and homeostasis. The ATP-binding cassette, subfamily B, member 6 (ABCB6), a membrane-associated protein transporting various molecules across extra- and intracellular membranes located on BTA 2, has been suggested to be involved in human iron homeostasis, mitochondrial respiratory function, and maintenance of mitochondrial DNA stability (Mitsuhashi et al., 2000) but could also represent zinc ion transmembrane transporter activity. The nuclear receptor subfamily 2 , group F, member 1 (NR2F1) gene located on BTA 7 (also known as the COUP-TF1) is known to selectively and noncovalently interact with metal ions (Ritchie et al., 1990). The strong genetic correlation and the common genomic regions identified in this study for iron and zinc content indicate that a marker-assisted selection program aimed at increasing the iron content in beef would have the added benefit of a concomitant increase in zinc content.

\section{Direct Genomic Value and Accuracy of Direct Genomic Value for Iron Concentration}

The accuracy of DGV is key to the successful application of genomic selection in animal breeding but cannot be assessed in the training set. In practice, cross validation can be performed in a sample of individuals that are related to those in the training set but that were not themselves included in training. We employed $\mathrm{K}$-means clustering to pedigree estimates of the additive genetic relationships among the genotyped animals to partition animals into training and validation groups, with the aim of increasing within-group and decreasing between-group relationships for cross validation. On the basis of the heritability estimates (Table 1), the proportion of phenotypic variation explained by the markers (Table 2), and practical considerations, we estimated the accuracy of DGV only for iron concentration. Using a bivariate animal model, the estimate for genetic correlation between DGV and iron concentration phenotype was $0.59 \pm 0.08$. The lack of reported accuracies of DGV for beef cattle does not allow for a direct comparison of this estimate; however, accuracies ranging from 0.22 to 0.69 were reported on 16 routinely recorded traits in 
American Angus beef (Saatchi et al., 2011), and a low accuracy of 0.3 was reported by Rolf et al. (2010) for ADFI, residual feed intake, and ADG. The estimated accuracy of 0.59 for the DGV for iron concentration indicates that selection based on genomic merit for iron concentration would be as efficient as selection based on individual phenotype for a trait with heritability of 0.35 .

Estimates of regression coefficients of phenotype (adjusted for contemporary groups fixed effect) on DGV for sodium and iron concentrations (Table 4), the $2 \mathrm{~min}$ erals with moderate and low heritability, were both lower than the expected value of 1.0. The regression analysis indicated that if DGV for iron were used in selection, for each unit ( $\mu \mathrm{g} / \mathrm{g}$ of meat) improvement in iron DGV there would be 0.73 units $(\mu \mathrm{g} / \mathrm{g}$ of meat) improvement in the actual iron concentration, which indicates that the DGV are biased upward, being more variable than they should.

\section{Iron Concentration and Selection}

It is increasingly clear that relative to the energy it contributes, the impact of red meat on the nutritional quality of the human diet via its contribution of protein and key micronutrients, such as iron and zinc, is underappreciated. For example, iron deficiency is the most common and widespread nutritional disorder in the world affecting both developing and industrialized nations (WHO Multicentre Growth Reference Study Group, 2006). In the United States and Europe the iron deficiency is greater, particularly in pregnant women and infants living in lower socioeconomic groups (Agostoni et al., 2008).

Aging adults, the fastest growing segment of the population in the United States, are at increased risk of sarcopenia, the degenerative loss of skeletal muscle mass and strength associated with aging, and are highly vulnerable to iron and zinc deficiency. Zinc deficiency, shown to increase with age, is associated with a decline of the immune system and increased inflammation associated with many health problems and a decrease in the ability of an organism to repair genetic damage when the amount of such damage is actually increasing (Wong and Ho, 2012). The best approach to reduce these risks is to ensure adequate intake of these micronutrients through diet, especially in the elderly, and the combination of protein and micronutrients provided by lean red meats is perfect for this purpose.

To ensure long-term sustainability of the industry, a beef cattle improvement program should consider traits that influence production efficiency, traits that influence the quality of the eating experience, traits that influence animal health and well-being, and traits that would provide health benefits to humans consuming the product. Increasing the concentration of iron and zinc in beef muscle through selection should benefit the beef cattle
Table 4. Estimates of coefficients and SE for regression of phenotype (adjusted for contemporary groups fixed effect) on direct genomic value (DGV) for sodium and iron concentrations ( $\mu \mathrm{g} / \mathrm{g}$ of meat) in LM in Angus cattle

\begin{tabular}{lcccc}
\hline \hline Mineral & Estimate & $\mathrm{SE}$ & $\mathrm{t}$ value & $P>|\mathrm{t}|$ \\
\hline Iron & 0.73 & 0.08 & 9.18 & $<0.0001$ \\
Sodium & 0.60 & 0.38 & 1.58 & 0.11 \\
\hline
\end{tabular}

industry as well as consumers by producing meat that is healthier for humans to eat and therefore encouraging consumption. In addition, increasing iron concentration in muscle would contribute to improved functionality of beef (defined as retention of red color at d 3 to 4 of retail display) and improved beef flavor. Vitamin $\mathrm{E}$ and iron content in muscle are the most important factors determining the functionality of meat, with redness being positively related to both vitamin $\mathrm{E}$ and heme iron content in lamb meat (Ponnampalam et al., 2012). Increasing iron content in muscle is expected to also improve color stability (shelf life) of beef at retail display. A significant genetic and phenotypic correlation was reported recently (Mateescu et al., 2013) between beef flavor and iron concentration, indicating an increase in iron concentration would contribute toward an improved beef flavor.

Before iron concentration in muscle can be considered as a candidate trait in future selection indices, genetic correlations with other traits under selection should be investigated, especially the genetic correlation between iron concentration and carcass traits. Toward this goal, phenotypic and genetic correlations between iron concentration and several economically important carcass traits are presented in Table 5. The genetic correlations of iron concentration with $\mathrm{HCW}$, percentage $\mathrm{KPH}$, marbling score, and rib eye area are not significantly different from 0 , indicating that selection for iron concentration is not likely to have unfavorable correlated effect on these carcass traits. A weak (0.22) genetic correlation was identified between iron content and USDA calculated yield grade. Although the SE of this correlation prohibits any decisive conclusions, the positive sign of this correlation suggests selection for increased iron concentration will not erode yield grade.

\section{Conclusion}

New advances in genomic technologies open up new and exciting opportunities for improvement of difficultto-measure traits like mineral concentration in beef. As per capita consumption of red meat has been declining mostly because of prevailing nutritional guidelines, increasing the concentration of key micronutrients is even 
Table 5. Means and SE for $\mathrm{HCW}$, percent $\mathrm{KPG}$, marbling score, rib eye area (REA), and USDA calculated yield grade $(Y G)$ and genetic $\left(R_{g}\right)$ and phenotypic $\left(R_{p}\right)$ correlations between carcass traits and iron concentration

\begin{tabular}{lcccc}
\hline \hline Trait & $\begin{array}{c}\text { No. of } \\
\text { observations }\end{array}$ & $\begin{array}{c}\text { Mean } \\
(\mathrm{SE})\end{array}$ & $\mathrm{R}_{\mathrm{g}}$ & $\mathrm{R}_{\mathrm{p}}$ \\
\hline $\mathrm{HCW}, \mathrm{kg}$ & 2,258 & $332.67(32.34)$ & $-0.01(0.14)$ & $0.02(0.02)$ \\
$\mathrm{KPH}, \%$ & 2,259 & $2.08(0.40)$ & $0.02(0.32)$ & $0.04(0.02)$ \\
Marbling score $^{1}$ & 2,258 & $5.96(1.04)$ & $0.15(0.12)$ & $0.02(0.03)$ \\
REA12, $^{2} \mathrm{~cm}^{2}$ & 2,259 & $81.23(8.00)$ & $-0.19(0.14)$ & $-0.01(0.02)$ \\
YG & 2,258 & $2.90(0.67)$ & $0.22(0.12)$ & $0.04(0.03)$ \\
\hline
\end{tabular}

${ }^{1}$ Marbling score: $3.0=$ traces; $4.0=$ slight; $5.0=$ small; $6.0=$ modest;

7.0 = moderate; 8.0 = slightly abundant; $9.0=$ moderately abundant.

${ }^{2} \mathrm{LM}$ cross-sectional area at carcass split between the 12 th and 13 th ribs.

more urgent and can be accomplished only through marker-assisted selection programs. This study found that iron content might be effectively manipulated through selection based on genomic merit, without negative impact on other carcass and palatability traits.

\section{LITERATURE CITED}

Agostoni, C., T. Decsi, M. Fewtrell, O. Goulet, S. Kolacek, B. Koletzko, K. F. Michaelsen, L. Moreno, J. Puntis, J. Rigo, R. Shamir, H. Szajewska, D. Turck, J. van Goudoever, and ESPGHAN Committee on Nutrition. 2008. Complementary feeding: A commentary by the ESPGHAN Committee on nutrition. J. Pediatr. Gastroenterol. Nutr. 46.:99-110.

Andrews, N. C. 2008. Forging a field: The golden age of iron biology. Blood 112:219-230.

AOAC. (2005). Official method 934.01. AOAC Int., Gaithersburg, MD.

Beard, J. L., and H. D. Dawson. 1997. Iron. In: B. L. O'Dell and R. A. Sunde, editors, Handbook of nutritionally essential minerals. Marcel Dekker, New York. p. 275-334.

Brown, D. H., W. P. Lafuse, and B. S. Zwilling. 1997. Stabilized expression of mRNA is associated with mycobacterial resistance controlled by Nramp1. Infect. Immun. 65:597-603.

Carpenter, C. E., and E. Clark. 1995. Evaluation of methods used in meat iron analysis and iron content of raw and cooked meats. J. Agric. Food Chem. 43:1824-1827.

Chen, J., M. Chloupkova, J. Gao, T. L. Chapman-Arvedson, and C. A. Enns. 2007. HFE modulates transferrin receptor 2 levels in hepatoma cells via interactions that differ from transferrin receptor 1-HFE interactions. J. Biol. Chem. 282:36862-36870.

Duan, Q., R.G. Tait Jr., M. S. Mayes, D. J. Garrick, Q. Liu, A. L. Van Eenennaam, R. G. Mateescu, D. L. Van Overbeke, A. J. Garmyn, D. C. Beitz, and J. M. Reecy. 2012. Genetic polymorphisms in bovine transferrin receptor 2 (TFR2) and solute carrier family 40 (ironregulated transporter), member 1 (SLC40A1) genes and their association with beef iron content. Anim. Genet. 43:115-122.

Eisenstein, R. S. 2000. Iron regulatory proteins and the molecular control of mammalian iron metabolism. Annu. Rev. Nutr. 20:627-662.

Fernando, R. L., and D. J. Garrick. 2010. GenSel-User manual for a portfolio of genomic selection related analyses. http://taurus. ansci.iastate.edu/. (Accessed 1 December 2012.)
Garmyn, A. J., G. G. Hilton, R. G. Mateescu, J. B. Morgan, J. M. Reecy, R. G. Tait Jr., D. C. Beitz, Q. Duan, J. P. Schoonmaker, M. S. Mayes, M. E. Drewnoski, Q. Lui, and D. L. Vanoverbeke. 2011. Estimation of relationships between mineral concentration and fatty acid composition of longissimus muscle and beef palatability traits. J. Anim. Sci. 89:2849-2858.

Gomes, M. S., and R. Appelberg. 1998. Evidence for a link between iron metabolism and Nramp1 gene function in innate resistance against Mycobacterium avium. Immunology 95:165-168.

Graham, R. M., A. C. Chua, C. E. Herbison, J. K. Olynyk, and D. Trinder. 2007. Liver iron transport. World J. Gastroenterol. 13:4725-4736.

Habier, D., R. L. Fernando, K. Kizilkaya, and D. J. Garrick. 2011. Extension of the Bayesian alphabet for genomic selection. BMC Bioinforma. 12:186.

Hentze, M. W., and L. C. Kuhn. 1996. Molecular control of vertebrate iron metabolism: MRNA-based regulatory circuits operated by iron, nitric oxide, and oxidative stress. Proc. Natl. Acad. Sci. U.S.A. 93:8175-8182.

Hu, Z., R. L. Fernando, D. J. Garrick, and J. M. Reecy. 2010. SNPlotz: A generic genome plot tool to aid the SNP association studies. BMC Bioinforma. 11(Suppl 4):P4.

Jorhem, L., and J. Engman. 2000. Determination of lead, cadmium, zinc, copper, and iron in foods by atomic absorption spectrometry after microwave digestion: NMKL collaborative study. J. AOAC Int. 83:1189-1203.

Kawabata, H., R. S. Germain, T. Ikezoe, X. Tong, E. M. Green, A. F. Gombart, and H. P. Koeffler. 2001. Regulation of expression of murine transferrin receptor 2. Blood 98:1949-1954.

Kizilkaya, K., R. L. Fernando, and D. J. Garrick. 2010. Genomic prediction of simulated multibreed and purebred performance using observed fifty thousand single nucleotide polymorphism genotypes. J. Anim. Sci. 88:544-551.

Lebron, J. A., A. P. West Jr., and P. J. Bjorkman. 1999. The hemochromatosis protein HFE competes with transferrin for binding to the transferrin receptor. J. Mol. Biol. 294:239-245.

Mateescu, R. G., A. J. Garmyn, R. G. Tait Jr., Q. Duan, Q. Liu, M. S. Mayes, D. J. Garrick, A. L. Van Eenennaam, D. L. VanOverbeke, G. G. Hilton, D. C. Beitz, and J. M. Reecy. 2013. Genetic parameters for concentrations of minerals in longissimus muscle and their associations with palatability traits in Angus cattle. J. Anim. Sci. 91:1067-1075.

Meuwissen, T. H., B. J. Hayes, and M. E. Goddard. 2001. Prediction of total genetic value using genome-wide dense marker maps. Genetics 157:1819-1829.

Meyer, K. 2007. WOMBAT: A tool for mixed model analyses in quantitative genetics by restricted maximum likelihood (REML). J. Zhejiang Univ. Sci. B 8:815-821.

Mitsuhashi, N., T. Miki, H. Senbongi, N. Yokoi, H. Yano, M. Miyazaki, N. Nakajima, T. Iwanaga, Y. Yokoyama, T. Shibata, and S. Seino. 2000. MTABC3, a novel mitochondrial ATPbinding cassette protein involved in iron homeostasis. J. Biol. Chem. 275:17536-17540.

Nicklas, T. A., C. E. O’Neil, M. Zanovec, D. R. Keast, and V. L. Fulgoni III. 2012. Contribution of beef consumption to nutrient intake, diet quality, and food patterns in the diets of the US population. Meat Sci. 90:152-158.

Ponnampalam, E. N., K. L. Butler, M. B. McDonagh, J. L. Jacobs, and D. L. Hopkins. 2012. Relationship between muscle antioxidant status, forms of iron, polyunsaturated fatty acids and functionality (retail colour) of meat in lambs. Meat Sci. 90:297-303.

Ritchie, H. H., L. H. Wang, S. Tsai, B. W. O’Malley, and M. J. Tsai. 1990. COUP-TF gene: A structure unique for the steroid/thyroid receptor superfamily. Nucleic Acids Res. 18:6857-6862. 
Rolf, M. M., J. F. Taylor, R. D. Schnabel, S. D. McKay, M. C. McClure, S. L. Northcutt, M. S. Kerley, and R. L. Weaber. 2010. Impact of reduced marker set estimation of genomic relationship matrices on genomic selection for feed efficiency in Angus cattle. BMC Genet. 11:24.

Saatchi, M., M. C. McClure, S. D. McKay, M. M. Rolf, J. Kim, J. E. Decker, T. M. Taxis, R. H. Chapple, H. R. Ramey, S. L. Northcutt, S. Bauck, B. Woodward, J. C. Dekkers, R. L. Fernando, R. D. Schnabel, D. J. Garrick, and J. F. Taylor. 2011. Accuracies of genomic breeding values in American Angus beef cattle using K-means clustering for cross-validation. Genet. Sel. Evol. 43:40.

Stein, L. D., C. Mungall, S. Shu, M. Caudy, M. Mangone, A. Day, E. Nickerson, J. E. Stajich, T. W. Harris, A. Arva, and S. Lewis. 2002. The generic genome browser: A building block for a model organism system database. Genome Res. 12:1599-1610.
Visscher, P. M., W. G. Hill, and N. R. Wray. 2008. Heritability in the genomics era-Concepts and misconceptions. Nat. Rev. Genet. 9:255-266.

WHO Multicentre Growth Reference Study Group. 2006. WHO child growth standards based on length/height, weight and age. Acta Paediatr. Suppl. 450:76-85.

Wong, C. P., and E. Ho. 2012. Zinc and its role in age-related inflammation and immune dysfunction. Mol. Nutr. Food Res. 56:77-87.

Wood, R. J., and A. G. Ronnenber. 2006. Iron. In: M. E. Shils, M. Shike, A. C. Ross, B. Caballero, and R. J. Cousins, editors, Modern nutrition in health and disease. Lippincott Williams \& Wilkins, Philadelphia. p. 248-270.

Zanovec, M., C. E. O’Neil, D. R. Keast, V. L. Fulgoni, and T. A. Nicklas. 2010. Lean beef contributes significant amounts of key nutrients to the diets of US adults: National Health and Nutrition Examination Survey 1999-2004. Nutr. Res. 30:375-381. 